\title{
The impact of host genetic background in the Pseudomonas aeruginosa respiratory infections
}

\author{
Nicola Ivan Loré ${ }^{1,2} \cdot$ Cristina Cigana $^{1} \cdot$ Barbara Sipione $^{1,2} \cdot$ Alessandra Bragonzi $^{1}$
}

Received: 5 March 2018 / Accepted: 5 June 2018 / Published online: 12 June 2018

(c) Springer Science+Business Media, LLC, part of Springer Nature 2018

\begin{abstract}
Understanding the significance of human genetic diversity in modulating host susceptibility to opportunistic infections is an emerging challenge in the field of respiratory illnesses. While it is recognized that diverse bacterial strains account for differential disease manifestations, emerging data indicate that host genetic diversity is an important determinant factor that influences the severity of opportunistic infections. With particular regard to respiratory illnesses mediated by the gramnegative bacterium Pseudomonas aeruginosa, diverse genetic background is also emerging as a key contributor. Humangenome-wide association studies are a common approach for determining the inter-individual genetic variation associated with variability of the pulmonary infections. Historically, diverse murine inbred mouse strains and ex-vivo cellular models were considered complementary to human studies for establishing the contribution of genetic background to $P$. aeruginosa respiratory infections. More recently, the development of a new mouse model of infection, mirroring human airway diseases, combined with innovative murine resource populations, modelling human genetic variation, provides additional insights into the mechanisms of genetic susceptibility. In this review, we cover the recent state of the art of human and animal studies and we discuss future potential challenges in the field of $P$. aeruginosa respiratory infections.
\end{abstract}

\section{Introduction}

Genetic diversity is a key determinant in modulating human susceptibility to several diseases, including the respiratory infections (Chapman and Hill 2012). The relevance of host genetic background in driving disease phenotypic diversity is also emerging in the context of monogenic diseases characterized by airway infection (Cutting 2015). Based on recent findings, we can now assume that pathogens are not the unique factors determining the wide spectrum of disease outcomes, as there is a considerable contribution from the host genetic background. The relevance of individual genetic variations to Pseudomonas aeruginosa infection is emerging in several respiratory illnesses of different etiologies including cystic fibrosis $(\mathrm{CF})$, chronic obstructive pulmonary

Nicola Ivan Loré

lore.nicolaivan@hsr.it

$\triangle$ Alessandra Bragonzi

bragonzi.alessandra@hsr.it

1 Division of Immunology, Transplantation and Infectious Diseases, Infections and Cystic Fibrosis Unit, IRCCS San Raffaele Scientific Institute, Milan, Italy

2 Vita-Salute San Raffaele University, Milan, Italy disease (COPD), or bronchiectasis. $P$. aeruginosa is one of the most common hospital-acquired opportunistic pathogens and mediates extremely variable outcomes of respiratory illnesses (Gellatly and Hancock 2013). So far, human studies have identified candidate genetic loci or modifier genes associated with the disease diversity during $P$. aeruginosa respiratory infection (Weiler and Drumm 2013). In parallel, several studies using animal and ex-vivo models have been carried over to achieve deep understanding of the biological relevance and significance of the host genetic profile in modulating the disease outcome of $P$. aeruginosa respiratory infection. Recently, the use of classical murine inbred strains and new murine resource populations has supported several progressive steps forward in this field, generating new knowledge with a strong translational significance. In this review, we discuss the latest state of the art that mainly covers human and murine studies to define the role of host genetic background and host genetic traits during respiratory infection by $P$. aeruginosa. 


\section{Heterogenicity of human populations results in different responses to $P$. aeruginosa infections}

Outcomes of $P$. aeruginosa infections in patients with respiratory illnesses are difficult to predict and show a high degree of variability in terms of disease severity, complications and survival (Chapman and Hill 2012; Cutting 2015). The association between genotype and phenotype is difficult to determine in humans due to the small size of cohorts with detailed clinical outcomes that are often influenced by non-genetic contributors, such as environmental and stochastic factors. The most characterized population, affected by respiratory infections, is that suffering from $\mathrm{CF}$ genetic disease and followed from birth; their clinical data, including their microbiological status (e.g., P. aeruginosa), are periodically recorded. In CF, it has been shown that host genetic factors (e.g., multiple genetic loci or polymorphic variations) influence the progression of $P$. aeruginosa lung infections and age at establishment, regardless of the Cystic Fibrosis Transmembrane Conductance Regulator (CFTR)-genotype. Two main genetic approaches have been exploited in humans to identify genetic modifiers that directly influence the phenotype of CF disease: (i) an "a priori" approach, i.e., the candidate gene approach, where the genes selected for investigation are identified from the current understanding of CF lung disease pathophysiology, and (ii) an "unbiased" approach, analyzing the whole genome or exome sequencing by linkage and genome-wide association studies (GWAS). From the candidate gene studies, several genes have been proposed as potential CF pulmonary disease phenotype modifiers (Weiler and Drumm 2013). These could be classified into different categories including inflammatory response, infection response, and tissue damage and repair.

Genetic association has been found for several phenotypes spanning from the age of first infection, establishment of chronic P. aeruginosa infection or particular $P$. aeruginosa phenotypes (e.g., mucoid). First acquisition of airway $P$. aeruginosa has been associated with variants in the mannose-binding lectin 2 (MBL2), in the $\mathrm{Na}^{+} / \mathrm{H}^{+}$exchanger (SCL9A3), in the amino acid transporter (SLC6A14) (Dorfman et al. 2008, 2011; Pereira et al. 2017) and in the tumor necrosis factor- $\alpha$ (TNF- $\alpha$ ) (Coutinho et al. 2014) genes. Significant associations between age-of-onset of chronic $P$. aeruginosa infection have been reported for ficolin ( $F N C 1, F N C 2$ ), MBL-associated serine protease (MASP3), caveolin-2 (CAV2), and transmembrane-like channel 6 (TMC6) genes (Dorfman et al. 2008; Emond et al. 2015; Haerynck et al. 2012). Time to first $P$. aeruginosa airway infection, chronic $P$. aeruginosa infection, and mucoid $P$. aeruginosa have been associated with genetic variants in dynactin protein
(DCTN4) (Emond et al. 2012). P. aeruginosa mucoidy has been associated with pro-inflammatory cytokines interleukin 8 (IL-8) gene variants (Furlan et al. 2016). However, even collectively, these human studies only partially explain the contribution of genetic variance to the risk of $P$. aeruginosa airway infection and should be validated in additional cohorts. Similar approaches should also be exploited in other populations affected by $P$. aeruginosa respiratory infection (e.g., COPD).

\section{Acute $P$. aeruginosa infection in resistant and susceptible inbred mouse strains}

Different mouse models of acute respiratory infection by $P$. aeruginosa have been used to dissect the role of genetic backgrounds in determining lung disease severity (Table 1). These models exploited and compared different inbred murine strains during acute pneumonia lasting for hours or at most a few days. In this regard, a comprehensive classification of mouse inbred strains into categories according to their resistance or susceptibility is difficult to achieve. The differences in the disease outcome may be affected by several factors including routes of administration (aerosol vs intratracheal), size of the bacterial load and different $P$. aeruginosa strains used (laboratory vs clinical), length of infection, as well as age, gender and the specific murine substrains. Despite these issues, a wide range of disease severity after $P$. aeruginosa infection with some common trends were observed indicating a critical role of the host genetic background in modulating the outcome of the pulmonary disease. Here, we focus mainly on the murine inbred strains most commonly tested in models of $P$. aeruginosa respiratory infection, namely $\mathrm{DBA} / 2, \mathrm{~A} / \mathrm{J}, \mathrm{C} 3 \mathrm{H} / \mathrm{He}, \mathrm{BALB} / \mathrm{c}$, and C57BL/6 mice (Table 1).

Susceptibility and resistance to $P$. aeruginosa infection were initially based on survival rates and bacterial loads in the lungs followed by additional characterization of immunological phenotypes. In an early extensive study, 11 inbred mouse strains were compared using aerosol models of $P$. aeruginosa infection (Wilson et al. 2007). DBA/2J mice were the most susceptible, while $\mathrm{A} / \mathrm{J}$ and $\mathrm{C} 3 \mathrm{H} / \mathrm{HeN}$ were the most resistant when monitored for mortality. In more details, the ability of the DBA/2J strain to contain bacterial growth in the lungs was limited and this supported the role of host genetic makeup in resistance to infections. Wilson et al. affirmed that this severe disease phenotypic trait was due to a limited bactericidal activity when compared with C57BL/6 macrophage cells (Wilson et al. 2007). Of note, these immune-mediated mechanistic conclusions were different to a previous study that focused on the macrophage phagocytic ability in different genetic backgrounds (Morissette et al. 1996), although both studies identified DBA/2J mice as susceptible murine strains. 
Table 1 Different outcomes to $P$. aeruginosa infection in murine inbred strains

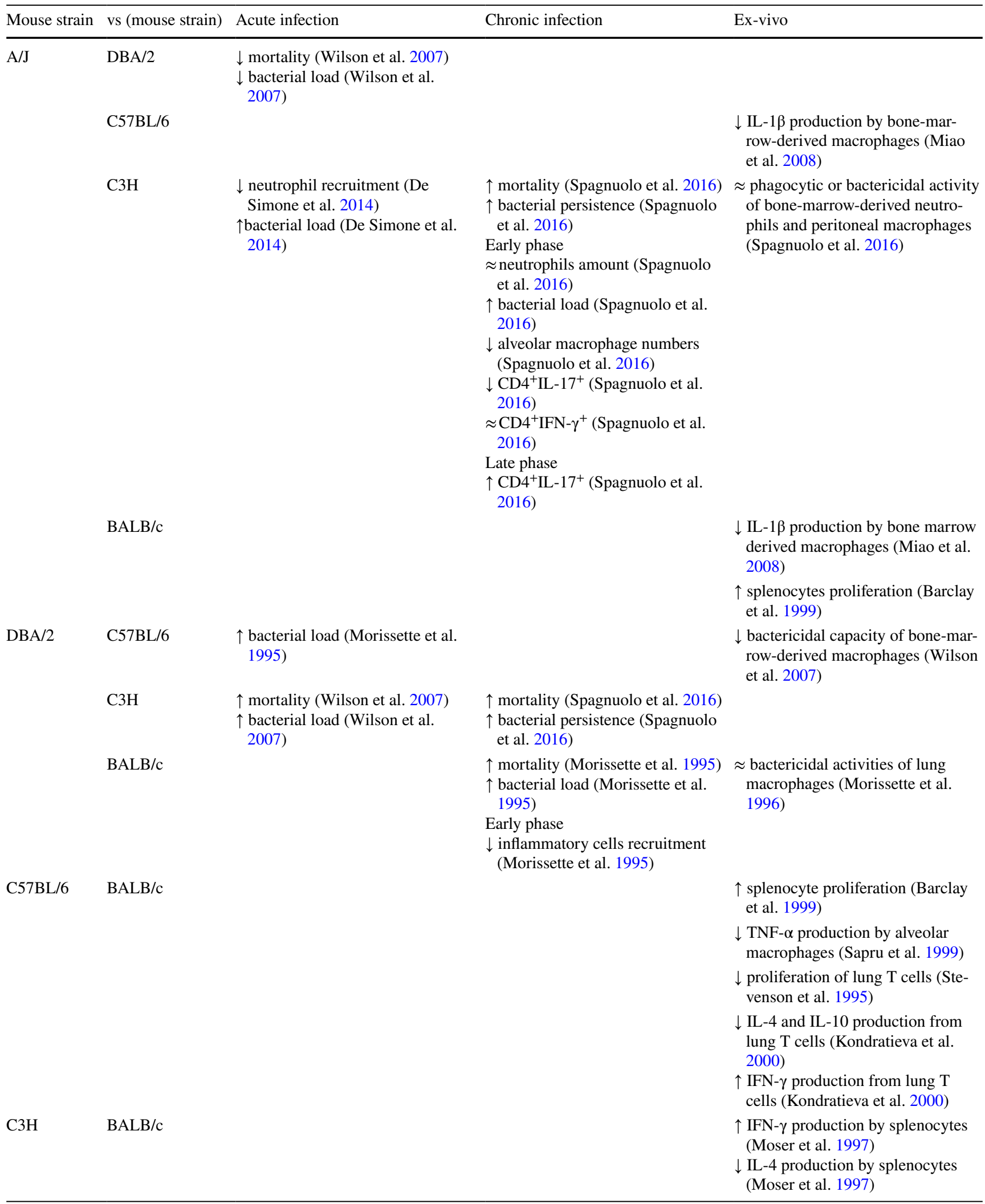


In a recent extensive study, we compared nine inbred mouse strains, including murine sub-strains, in a pneumonia model system induced by intratracheal delivery of the $P$. aeruginosa clinical strain to define deviant survival phenotypes. The highest susceptibility was observed in $\mathrm{A} / \mathrm{J}$ and $\mathrm{DBA} / 2 \mathrm{~J}$, while $\mathrm{BALB} / \mathrm{cAnNCrl}$ and $\mathrm{C} 3 \mathrm{H} / \mathrm{HeOuJ}$ were the most resistant to $P$. aeruginosa infection (De Simone et al. 2014). When distinct sub-strains of BALB/c from Jackson (BALB/cJ and BALB/cByJ) or Charles River (BALB/cAnNCrl) were compared, significant differences between BALB/cAnNCrl and BALB/cByJ were found supporting marked genetic and behavioral differences. A more detailed characterization of immunological phenotype was carried out on $\mathrm{A} / \mathrm{J}$ and $\mathrm{C} 3 \mathrm{H} / \mathrm{HeOuJ}$ mice, as the most deviant murine strains (De Simone et al. 2014). When bacterial loads and neutrophils recovered in the lungs were correlated, A/J mice showed a delayed neutrophil recruitment and a higher bacterial burden in the lungs, suggesting their inefficiency to promptly keep the bacterial infection in check compared to $\mathrm{C} 3 \mathrm{H} / \mathrm{HeOuJ}$ mice. We speculated that $\mathrm{A} / \mathrm{J}$ mice do not mount a proper, early immune defense leading to a permissive environment for bacterial replication and bacteremia, ultimately leading to rapid disease progression. Furthermore, A/J mice showed an excessive release of pro-inflammatory cytokines that did not correlate with the cellular response, suggesting a defect in leukocyte recruitment. As stated above, variability in the methods of infection (aerosol vs intratracheal) and measurable outcomes (body weight vs mortality vs bacterial load vs inflammation) are two key factors affecting the interpretation of the results. Therefore, a direct comparison among studies should be carefully weighted. Based on the definition of host resistance to infection (Schneider and Ayres 2008), an accurate evaluation of bacterial loads at different post-infection timepoints may represent the most unbiased biological parameter for comparing results across different studies.

Mouse strains presenting deviant disease phenotypes can be further exploited to identify genetic loci underlying host susceptibility to infections of different origins (Gruenheid and Gros 2010; Vidal et al. 2008). While the forward genetic approach has been widely implemented for several pathogens, only one study has applied it to $P$. aeruginosa infection. In this regard, we mated $P$. aeruginosa-resistant $\mathrm{C} 3 \mathrm{H} / \mathrm{HeOuJ}$, and susceptible $\mathrm{A} / \mathrm{J}$ mice and the deriving $\mathrm{F} 2$ intercross population was phenotyped and used for quantitative trait locus (QTL) mapping (De Simone et al. 2016). A significant QTL associated with the survival rate was mapped on chromosome 6 , and named $P$. aeruginosa infection resistance locus 1 (Pairl1). Through gene prioritization analysis within the Pairll genomic interval ( $20 \mathrm{Mbps})$, a set of promising candidate disease modifier genes was proposed that mediated host-pathogen sensing, neutrophils and macrophages recruitment, and inflammatory processes.

It is becoming evident that complex combinations and variations of genetic locus/genes affect the outcome of $P$. aeruginosa respiratory infection. Although mouse inbred strains are the starting point for the exploration of causal genotype-phenotype relationships and gene mapping, they do not offer a wide genetic variability for the identification and study of the polymorphic variations that are hallmarks of the human population (Peters et al. 2007). This limits genetic and phenotypic diversity and the value of QTL detection. The new Collaborative Cross (CC) mice population may overcome the limitation of previous genetic mapping approach (Churchill et al. 2004), such as the low mapping resolution based on $\mathrm{F} 2$ intercross population. The CC is a murine inbred reference population with high genetic diversity designed by randomly outcrossing eight founder inbred strains, followed by inbreeding processes (https:// csbio.unc.edu/CCstatus/index.py). It is worth noting that the $\mathrm{CC}$ murine population has been used to model infectious diseases caused by a number of different virus and bacteria including Ebola virus (Rasmussen et al. 2014), Mycobacterium tuberculosis (Smith et al. 2016), West Nile virus (Graham et al. 2015), Severe Acute Respiratory Coronavirus (SARS-CoV) (Gralinski et al. 2015), influenza A virus (Ferris et al. 2013), and non-typhoidal Salmonella (Zhang et al. 2018). In these studies, the power of the CC resource led to the identification of the host genes controlling susceptibility to infections. When we challenged a cohort of 17 different CC murine strains with $P$. aeruginosa into the lung, they displayed a widely marked phenotypic disease variation in terms of mortality (survival rate) and morbidity (changes in body weight). When broad-sense heritability of these phenotypic traits was evaluated, we confirmed the influence of the genetic profile, rather than environmental factors, among CC lines during $P$. aeruginosa infection (Lore et al. 2015). This study confirmed the ability the $\mathrm{CC}$ murine population has to mirror human disease diversity in the context of acute lung infection by $P$. aeruginosa. It is evident that the CC population may be exploited to identify genetic loci associated with acute lung infection by $P$. aeruginosa, with a higher mapping resolution in comparison to previous studies.

\section{Susceptibility to chronic $P$. aeruginosa respiratory infection in inbred mouse strains}

Studies with different inbred mouse strains support the contribution of the host genetic background to predispose the animals to chronic infection and different degrees of disease severity due to a different immunoreactivity to pathogens (Table 1). In this regard, several mouse models of chronic infection have been established by including $P$. aeruginosa clinical isolates in different types of immobilizing agents 
such as agar, agarose, or seaweed alginate to prevent clearance by the host (Bragonzi 2010). Recently, we exploited the agar-beads mouse model of long-term chronic lung infection, refined and characterized in $\mathrm{C} 57 \mathrm{Bl} / 6 \mathrm{NCrl}$ (Cigana et al. 2016), in five phylogenetically different inbred strains of mice to identify deviant disease phenotypes and to dissect the cell-mediated immunity (Spagnuolo et al. 2016). In this study, we classified $\mathrm{A} / \mathrm{J}$ and DBA/2J as the most susceptible to $P$. aeruginosa chronic infection, while $\mathrm{C} 3 \mathrm{H} /$ $\mathrm{HeOuJ}$ strains were classified as the most resistant. Several clinical phenotypes including survival rates, weight losses, bacterial loads and capacity to establish long-term chronic infection were considered in this ranking. Other works that focused on chronic infection mediated by bacteria embedded in agar-beads are generally in agreement with this classification and in addition include BALB/c as a resistant murine strain (Morissette et al. 1995; Tam et al. 1999). Moreover, a different classification for $\mathrm{C} 57 \mathrm{Bl} / 6 \mathrm{~N}$ susceptibility to chronic infection was reported, probably due to the use of different bacterial strains embedded in agar-beads. To define possible causes for predisposition, immune-related events possibly linked to diverse $P$. aeruginosa susceptibility and resistance have been investigated. Morissette et al. reported that in a model of $P$. aeruginosa chronic infection, leukocyte recruitment in the early phases of infection was higher in resistant hosts compared to susceptible ones. This could account for a differential predisposition to the development of chronic infection (Morissette et al. 1995; Spagnuolo et al. 2016). In line with this work, we found in the early phase of chronic infection that neutrophils were similar in the lungs of susceptible $\mathrm{A} / \mathrm{J}$ and resistant $\mathrm{C} 3 \mathrm{H} / \mathrm{HeOuJ}$ strains, despite higher bacterial loads in susceptible mice; in addition, resistant mice showed higher alveolar macrophage numbers. Immunity mediated by T-helper (Th) cell subsets, such as $\mathrm{CD} 4+\mathrm{T}$ cells, may play a critical role in host protection vs immunopathology of infectious diseases. Early studies in the seaweed alginate beads model had defined Th1 (IFN $\gamma$ -producing $\mathrm{CD}^{+}{ }^{+} \mathrm{T}$ ) response of resistant $\mathrm{C} 3 \mathrm{H} / \mathrm{HeN}$ mice as being associated with a better disease outcome when compared to the Th2 (IL4-producing $\mathrm{CD}^{+} \mathrm{T}$ ) response of susceptible BALB/c mice (Moser et al. 1999, 1997). While the Th1/Th2 paradigm dominated the field of $P$. aeruginosaassociated immunological responses, the discovery of a third subset of IL-17-producing effector Th cells has fostered new hypotheses. Indeed, we have recently demonstrated that the IL-17-mediated immune response may be beneficial in the early phase chronic infection by contrasting $P$. aeruginosa, while its overload can be detrimental in the advanced phase by exacerbating immunopathology (Lore et al. 2016a, b). In line with this report, by comparing different murine inbred strains, we showed that the high clearance of $P$. aeruginosa and the progressive resolution of inflammation in resistant $\mathrm{C} 3 \mathrm{H} / \mathrm{HeOuJ}$ mice was associated with early superior lung infiltration by an IL17-dominated T-cell response (Spagnuolo et al. 2016). Instead, IL4-producing $\mathrm{CD} 4^{+} \mathrm{T}$ cells were negligible in both resistant $\mathrm{C} 3 \mathrm{H} / \mathrm{HeOuJ}$ and susceptible $\mathrm{A} / \mathrm{J}$ mice, while levels of IFN $\gamma$-producing $\mathrm{CD}^{+}{ }^{+} \mathrm{T}$ cells were similar in the early stage chronic infection. In the late phase, susceptible $\mathrm{A} / \mathrm{J}$ mice showed a massive infiltration of the lung by $\mathrm{CD} 4{ }^{+} \mathrm{IL} 17^{+}$cells compared to $P$. aeruginosaresistant strain associated with an exacerbated immunopathology. Thus, host genetic backgrounds predisposing to the modulation of IL17-mediated immunity can determine the outcomes of early and advanced chronic $P$. aeruginosa respiratory infection. These results open up new avenues for translational studies aimed at testing new therapeutic approaches.

As in the context of acute respiratory infection, mouse strains presenting deviant disease and immunological phenotypes can be further exploited to identify genetic loci underlying host susceptibility to chronic respiratory infection. At the time of writing, human and murine studies addressing the role of genetic traits associated with chronic respiratory infection are limited. Thus, future efforts exploiting new murine population (e.g., CC mice) may contribute to new knowledge in this field.

\section{Dissection of mechanisms underlying murine susceptibility to $P$. aeruginosa infection in ex-vivo models}

The use of ex-vivo models has been exploited but not widely implemented to investigate the cellular/molecular mechanisms underlying the impact of host genetics on the susceptibility to $P$. aeruginosa infection (Table 1 ). Innate immune recognition and clearance mechanisms play a critical role in controlling $P$. aeruginosa. The host genetic background could influence the neutrophil and macrophage capacity to phagocytize and kill $P$. aeruginosa. Despite an initial increase in phagocytosis, bone-marrow-derived macrophages of susceptible DBA/2 displayed a severely reduced bactericidal capacity compared to those of C57BL/6 macrophages resistant to $P$. aeruginosa infection (Wilson et al. 2007). Differently, the in vitro bactericidal activity of resident and inflammatory alveolar and interstitial macrophages recruited did not differ between susceptible $\mathrm{DBA} / 2$ and $\mathrm{BALB} / \mathrm{c}$ mice resistant to $P$. aeruginosa infection (Morissette et al. 1996). The different origins of macrophages (bone marrow vs lung) could explain the different results of these reports. However, in our recent report, we did not find differences either in phagocytizing or bactericidal activities of bone-marrow-derived neutrophils and peritoneal macrophages from susceptible $\mathrm{A} / \mathrm{J}$ and resistant $\mathrm{C} 3 \mathrm{H} / \mathrm{HeOuJ}$ mice, suggesting that the different outcomes of diverse genetic backgrounds to $P$. aeruginosa infection cannot be assigned to the bactericidal activity of phagocytosing 
cells (Spagnuolo et al. 2016). It is worth noting that the tissue origin may account for a different stage of neutrophil differentiation and function. Thus, future studies focusing on neutrophil cells isolated from murine lungs or airways during an inflammatory response should light on the role of the host genetic background in this context.

Immune cells derived from susceptible and resistant mouse strains could produce different amounts of cytokines/ chemokines thus impacting on leukocyte recruitment. It has been demonstrated that alveolar macrophages from resistant $\mathrm{BALB} / \mathrm{c}$ mice produce significantly higher levels of TNF- $\alpha$ following stimulation with heat-killed $P$. aeruginosa compared to those from susceptible C57BL/6 mice (Sapru et al. 1999). Bone-marrow-derived macrophages from $\mathrm{A} / \mathrm{J}$ mice secrete less IL- $1 \beta$ protein than those from C57B1/6 and $\mathrm{BALB} / \mathrm{c}$ mice when stimulated in vitro by $P$. aeruginosa (Miao et al. 2008).

The genetic background may also influence T-cell responses. Splenocytes from A/J and $\mathrm{C} 57 \mathrm{Bl} / 6$ mice were found to be high responders to proliferation stimulated in vitro by $P$. aeruginosa exoenzyme $\mathrm{S}$, while BALB/c mice were low responders (Barclay et al. 1999). Taking into consideration that the authors identified $\mathrm{A} / \mathrm{J}$ and $\mathrm{C} 57 \mathrm{Bl} / 6$ mice as susceptible to $P$. aeruginosa infection and $\mathrm{BALB} / \mathrm{c}$ mice as resistant, they speculated that lymphocyte proliferation could impair the host response to $P$. aeruginosa. Differently, it has been shown that heat-killed $P$. aeruginosa induced significantly higher in vitro proliferative responses of lung $\mathrm{T}$ cells from resistant $\mathrm{BALB} / \mathrm{c}$ than those from susceptible C57Bl/6 mice (Stevenson et al. 1995). However, the differences between the last two reports could result from the origin of T cells (spleen vs lung) as well as the use of different P. aeruginosa factors. Afterwards, the latter group showed that T-cell clones derived from lymph nodes and lungs of different mouse strains produced different cytokines following treatment with heat-killed $P$. aeruginosa. T-cell clones from resistant BALB/c mice produced more IL-4 and IL-10 and were annotated as Th2-like cells, while those from susceptible C57B1/6 mice produced more IFN- $\gamma$ and were considered Th1-like cells (Kondratieva et al. 2000). Other studies on ex-vivo polarization of Th cells from different mouse strains showed divergent results. Splenic cells from resistant $\mathrm{C} 3 \mathrm{H} / \mathrm{HeN}$ mice produced more IFN- $\gamma$ following stimulation with $P$. aeruginosa outer membrane protein, while those from susceptible BALB/c mice produced more IL-4 (Moser et al. 1997). The Th1 polarization in resistant mouse strains is in line with the observation that this type of response is commonly associated with $P$. aeruginosa clearance or with a milder course of the infection (Yonker et al. 2015).

It is clear from these ex-vivo studies that several contrasting results have been reported probably reflecting the complexity of the host $-P$. aeruginosa interplay. Differences among studies may reflect experimental models of infection, the inbred mouse sub-strains, the use of different $P$. aeruginosa strains or its products, the type of cells stimulated, their physical origin, the timing and other unconsidered confounders.

\section{Conclusions}

The relevance of the inter-individual genetic variation, intended as the diversity of host genetic backgrounds or host genetic modifier locus/i, has emerged in the context of respiratory infection by $P$. aeruginosa. Several proofs have been produced thanks to the complementary findings of both human and animal studies. However, additional efforts are required to clearly identify the candidate host genetic modifier locus/i with translational potential. As discussed in this review, genetics-based variability in the disease outcomes evidenced by animal models, and in particular different inbred murine strains, represents important progress in the field, at least in the context of $P$. aeruginosa infection. Overall, these studies highlight how mouse models can be exploited to mirror host genetic diversity and the associated host defense variations. Future studies may exploit CC mice and mouse models of $P$. aeruginosa infection and will reveal genetic loci associated with the severity of acute or chronic lung infection as previously demonstrated for other respiratory pathogens (Ferris et al. 2013; Gralinski et al. 2015). Further efforts should aim at confirming the potential biological and translational relevance in humans in the context of respiratory infection induced by $P$. aeruginosa. Regarding rare monogenic diseases characterized by airway infection (e.g., CF), new mouse models mirroring inter-individual genetic variation are essential to advance or complement human studies, currently limited by the small size of cohorts and phenotypic data. Once more, the CC or the Diversity Outbred (DO) mice represent strong tools for the future to model genetic diversity of monogenic diseases, providing new knowledge in this research area.

Moreover, refined mouse models of infection may prove to be essential to determine the relevance of genetic diversity in modulating differential activation of the immune system during $P$. aeruginosa respiratory infection. As we discussed in this review, previous studies had highlighted the potential role of mouse inbred strains in this field, although they do not completely reflect the host genetic variability in humans. In this regard, to our knowledge, no data from ex-vivo studies on CC- or DO-derived cells stimulated by $P$. aeruginosa have been published. However, the availability of powerful tools, as CC and DO mice, may be essential to associate in vivo phenotypic descriptive investigations to in vitro mechanistic studies in these populations to identify pathways involved in the host susceptibility to $P$. aeruginosa lung infection. 
In conclusion, further efforts are required to correlate human and animal data. The technological advancement of DNA sequencing and analysis both in humans and animals has given a significant boost to studies in this field. This will allow the scientific community to identify novel candidate modifiers of genetic loci or genes with a translational clinical relevance in the context of $P$. aeruginosa respiratory infection.

Acknowledgements This study has been funded by the Italian CF Research Foundation (FFC\#9/2014 and FFC\#15/2016) to A.B.; by Italian CF Research Foundation (FFC\#11/2015 and FFC\#04/2017), by a Research Grant 2016 by the European Society of Clinical Microbiology and Infectious Diseases (ESCMID), by Short Term Scientific Mission (SYSGENET network BM0901) and by European Respiratory Society Fellowship (STRTF 2014-5493) to N.I.L.

\section{References}

Barclay NG, Spurrell JC, Bruno TF, Storey DG, Woods DE, Mody CH (1999) Pseudomonas aeruginosa exoenzyme $\mathrm{S}$ stimulates murine lymphocyte proliferation in vitro. Infect Immun 67:4613-4619

Bragonzi A (2010) Murine models of acute and chronic lung infection with cystic fibrosis pathogens. Int J Med Microbiol 300(8):584-593

Chapman SJ, Hill AV (2012) Human genetic susceptibility to infectious disease. Nat Rev Genet 13:175-188

Churchill GA, Airey DC, Allayee H, Angel JM, Attie AD, Beatty J, Beavis WD, Belknap JK, Bennett B, Berrettini W, Bleich A, Bogue M, Broman KW, Buck KJ, Buckler E, Burmeister M, Chesler EJ, Cheverud JM, Clapcote S, Cook MN, Cox RD, Crabbe JC, Crusio WE, Darvasi A, Deschepper CF, Doerge RW, Farber CR, Forejt J, Gaile D, Garlow SJ, Geiger H, Gershenfeld H, Gordon T, Gu J, Gu W, de Haan G, Hayes NL, Heller C, Himmelbauer H, Hitzemann R, Hunter K, Hsu HC, Iraqi FA, Ivandic B, Jacob HJ, Jansen RC, Jepsen KJ, Johnson DK, Johnson TE, Kempermann G, Kendziorski C, Kotb M, Kooy RF, Llamas B, Lammert F, Lassalle JM, Lowenstein PR, Lu L, Lusis A, Manly KF, Marcucio R, Matthews D, Medrano JF, Miller DR, Mittleman G, Mock BA, Mogil JS, Montagutelli X, Morahan G, Morris DG, Mott R, Nadeau JH, Nagase H, Nowakowski RS, O'Hara BF, Osadchuk AV, Page GP, Paigen B, Paigen K, Palmer AA, Pan HJ, Peltonen-Palotie L, Peirce J, Pomp D, Pravenec M, Prows DR, Qi Z, Reeves RH, Roder J, Rosen GD, Schadt EE, Schalkwyk LC, Seltzer Z, Shimomura K, Shou S, Sillanpaa MJ, Siracusa LD, Snoeck HW, Spearow JL, Svenson K, Tarantino LM, Threadgill D, Toth LA, Valdar W, de Villena FP, Warden C, Whatley S, Williams RW, Wiltshire T, Yi N, Zhang D, Zhang M, Zou F (2004) The Collaborative Cross, a community resource for the genetic analysis of complex traits. Nat Genet 36:1133-1137

Cigana C, Lore NI, Riva C, De Fino I, Spagnuolo L, Sipione B, Rossi G, Nonis A, Cabrini G, Bragonzi A (2016) Tracking the immunopathological response to Pseudomonas aeruginosa during respiratory infections. Sci Rep 6:21465

Coutinho CA, Marson FA, Marcelino AR, Bonadia LC, Carlin MP, Ribeiro AF, Ribeiro JD, Bertuzzo CS (2014) TNF-alpha polymorphisms as a potential modifier gene in the cystic fibrosis. Int J Mol Epidemiol Genet 5:87-99

Cutting GR (2015) Cystic fibrosis genetics: from molecular understanding to clinical application. Nat Rev Genet 16:45-56

De Simone M, Spagnuolo L, Lore NI, Rossi G, Cigana C, De Fino I, Iraqi FA, Bragonzi A (2014) Host genetic background influences the response to the opportunistic Pseudomonas aeruginosa infection altering cell-mediated immunity and bacterial replication. PLoS ONE 9:e106873

De Simone M, Spagnuolo L, Lore NI, Cigana C, De Fino I, Broman KW, Iraqi FA, Bragonzi A (2016) Mapping genetic determinants of host susceptibility to Pseudomonas aeruginosa lung infection in mice. BMC Genom 17:351

Dorfman R, Sandford A, Taylor C, Huang B, Frangolias D, Wang Y, Sang R, Pereira L, Sun L, Berthiaume Y, Tsui LC, Pare PD, Durie P, Corey M, Zielenski J (2008) Complex two-gene modulation of lung disease severity in children with cystic fibrosis. J Clin Investig 118:1040-1049

Dorfman R, Taylor C, Lin F, Sun L, Sandford A, Pare P, Berthiaume Y, Corey M, Durie P, Zielenski J (2011) Modulatory effect of the SLC9A3 gene on susceptibility to infections and pulmonary function in children with cystic fibrosis. Pediatr Pulmonol 46:385-392

Emond MJ, Louie T, Emerson J, Zhao W, Mathias RA, Knowles MR, Wright FA, Rieder MJ, Tabor HK, Nickerson DA, Barnes KC, Gibson RL, Bamshad MJ (2012) Exome sequencing of extreme phenotypes identifies DCTN4 as a modifier of chronic Pseudomonas aeruginosa infection in cystic fibrosis. Nat Genet 44:886-889

Emond MJ, Louie T, Emerson J, Chong JX, Mathias RA, Knowles MR, Rieder MJ, Tabor HK, Nickerson DA, Barnes KC, Go L, Gibson RL, Bamshad MJ (2015) Exome sequencing of phenotypic extremes identifies CAV2 and TMC6 as interacting modifiers of chronic Pseudomonas aeruginosa infection in cystic fibrosis. PLoS Genet 11:e1005273

Ferris MT, Aylor DL, Bottomly D, Whitmore AC, Aicher LD, Bell TA, Bradel-Tretheway B, Bryan JT, Buus RJ, Gralinski LE, Haagmans BL, McMillan L, Miller DR, Rosenzweig E, Valdar W, Wang J, Churchill GA, Threadgill DW, McWeeney SK, Katze MG, PardoManuel de Villena F, Baric RS, Heise MT (2013) Modeling host genetic regulation of influenza pathogenesis in the collaborative cross. PLoS Pathog 9:e1003196

Furlan LL, Marson FAL, Ribeiro JD, Bertuzzo CS, Junior JBS, Souza DRS (2016) IL8 gene as modifier of cystic fibrosis: unraveling the factors which influence clinical variability. Hum Genet 135(8):881-894

Gellatly SL, Hancock RE (2013) Pseudomonas aeruginosa: new insights into pathogenesis and host defenses. Pathog Dis 67:159-173

Graham JB, Thomas S, Swarts J, McMillan AA, Ferris MT, Suthar MS, Treuting PM, Ireton R, Gale M Jr, Lund JM (2015) Genetic diversity in the collaborative cross model recapitulates human West Nile virus disease outcomes. MBio 6:e00493-00415

Gralinski LE, Ferris MT, Aylor DL, Whitmore AC, Green R, Frieman MB, Deming D, Menachery VD, Miller DR, Buus RJ, Bell TA, Churchill GA, Threadgill DW, Katze MG, McMillan L, Valdar W, Heise MT, Pardo-Manuel de Villena F, Baric RS (2015) Genome wide identification of SARS-CoV susceptibility loci using the collaborative cross. PLoS Genet 11:e1005504

Gruenheid S, Gros P (2010) Forward genetic dissection of innate response to infection in inbred mouse strains: selected success stories. Clin Exp Immunol 162:393-401

Haerynck F, Van Steen K, Cattaert T, Loeys B, Van Daele S, Schelstraete P, Claes K, Van Thielen M, De Canck I, Mahachie John JM, De Baets F (2012) Polymorphisms in the lectin pathway genes as a possible cause of early chronic Pseudomonas aeruginosa colonization in cystic fibrosis patients. Hum Immunol 73:1175-1183

Kondratieva TK, Kobets NV, Khaidukov SV, Yeremeev VV, Lyadova IV, Apt AS, Tam MF, Stevenson MM (2000) Characterization of T cell clones derived from lymph nodes and lungs of Pseudomonas aeruginosa-susceptible and resistant mice following immunization with heat-killed bacteria. Clin Exp Immunol 121:275-282 
Lore NI, Iraqi FA, Bragonzi A (2015) Host genetic diversity influences the severity of Pseudomonas aeruginosa pneumonia in the Collaborative Cross mice. BMC Genet 16:106

Lore NI, Bragonzi A, Cigana C (2016a) The IL-17A/IL-17RA axis in pulmonary defence and immunopathology. Cytokine Growth Factor Rev 30:19-27

Lore NI, Cigana C, Riva C, De Fino I, Nonis A, Spagnuolo L, Sipione B, Cariani L, Girelli D, Rossi G, Basso V, Colombo C, Mondino A, Bragonzi A (2016b) IL-17A impairs host tolerance during airway chronic infection by Pseudomonas aeruginosa. Sci Rep 6:25937

Miao EA, Ernst RK, Dors M, Mao DP, Aderem A (2008) Pseudomonas aeruginosa activates caspase 1 through Ipaf. Proc Natl Acad Sci USA 105:2562-2567

Morissette C, Skamene E, Gervais F (1995) Endobronchial inflammation following Pseudomonas aeruginosa infection in resistant and susceptible strains of mice. Infect Immun 63:1718-1724

Morissette C, Francoeur C, Darmond-Zwaig C, Gervais F (1996) Lung phagocyte bactericidal function in strains of mice resistant and susceptible to Pseudomonas aeruginosa. Infect Immun 64:4984-4992

Moser C, Johansen HK, Song Z, Hougen HP, Rygaard J, Hoiby N (1997) Chronic Pseudomonas aeruginosa lung infection is more severe in Th2 responding BALB/c mice compared to Th1 responding $\mathrm{C} 3 \mathrm{H} / \mathrm{HeN}$ mice. APMIS 105:838-842

Moser C, Hougen HP, Song Z, Rygaard J, Kharazmi A, Hoiby N (1999) Early immune response in susceptible and resistant mice strains with chronic Pseudomonas aeruginosa lung infection determines the type of T-helper cell response. APMIS 107:1093-1100

Pereira SV, Ribeiro JD, Bertuzzo CS, Marson FAL (2017) Association of clinical severity of cystic fibrosis with variants in the SLC gene family (SLC6A14, SLC26A9, SLC11A1 and SLC9A3). Gene 629:117-126

Peters LL, Robledo RF, Bult CJ, Churchill GA, Paigen BJ, Svenson KL (2007) The mouse as a model for human biology: a resource guide for complex trait analysis. Nat Rev Genet 8:58-69

Rasmussen AL, Okumura A, Ferris MT, Green R, Feldmann F, Kelly SM, Scott DP, Safronetz D, Haddock E, LaCasse R, Thomas MJ, Sova P, Carter VS, Weiss JM, Miller DR, Shaw GD, Korth MJ, Heise MT, Baric RS, de Villena FP, Feldmann H, Katze MG (2014) Host genetic diversity enables Ebola hemorrhagic fever pathogenesis and resistance. Science 346:987-991
Sapru K, Stotland PK, Stevenson MM (1999) Quantitative and qualitative differences in bronchoalveolar inflammatory cells in Pseudomonas aeruginosa-resistant and -susceptible mice. Clin Exp Immunol 115:103-109

Schneider DS, Ayres JS (2008) Two ways to survive infection: what resistance and tolerance can teach us about treating infectious diseases. Nat Rev Immunol 8:889-895

Smith CM, Proulx MK, Olive AJ, Laddy D, Mishra BB, Moss C, Gutierrez NM, Bellerose MM, Barreira-Silva P, Phuah JY, Baker RE, Behar SM, Kornfeld H, Evans TG, Beamer G, Sassetti CM (2016) Tuberculosis susceptibility and vaccine protection are independently controlled by host genotype. MBio 7(5):e01516

Spagnuolo L, De Simone M, Lore NI, De Fino I, Basso V, Mondino A, Cigana C, Bragonzi A (2016) The host genetic background defines diverse immune-reactivity and susceptibility to chronic Pseudomonas aeruginosa respiratory infection. Sci Rep 6:36924

Stevenson MM, Kondratieva TK, Apt AS, Tam MF, Skamene E (1995) In vitro and in vivo $\mathrm{T}$ cell responses in mice during bronchopulmonary infection with mucoid Pseudomonas aeruginosa. Clin Exp Immunol 99:98-105

Tam M, Snipes GJ, Stevenson MM (1999) Characterization of chronic bronchopulmonary Pseudomonas aeruginosa infection in resistant and susceptible inbred mouse strains. Am J Respir Cell Mol Biol 20:710-719

Vidal SM, Malo D, Marquis JF, Gros P (2008) Forward genetic dissection of immunity to infection in the mouse. Annu Rev Immunol 26:81-132

Weiler CA, Drumm ML (2013) Genetic influences on cystic fibrosis lung disease severity. Front Pharmacol 4:40

Wilson KR, Napper JM, Denvir J, Sollars VE, Yu HD (2007) Defect in early lung defence against Pseudomonas aeruginosa in DBA/2 mice is associated with acute inflammatory lung injury and reduced bactericidal activity in naive macrophages. Microbiology 153:968-979

Yonker LM, Cigana C, Hurley BP, Bragonzi A (2015) Host-pathogen interplay in the respiratory environment of cystic fibrosis. J Cyst Fibros 14:431-439

Zhang J, Malo D, Mott R, Panthier JJ, Montagutelli X, Jaubert J (2018) Identification of new loci involved in the host susceptibility to Salmonella Typhimurium in collaborative cross mice. BMC Genom 19:303 